\title{
The mechanism of wrinkling of cotton fabric in a front loading washer: the effect of mechanical action
}

DOI:

$10.1177 / 0040517518821909$

Document Version

Accepted author manuscript

Link to publication record in Manchester Research Explorer

\section{Citation for published version (APA):}

Liu, H., Gong, R., Xu, P., Ding, X., \& Wu, X. (2019). The mechanism of wrinkling of cotton fabric in a front loading washer: the effect of mechanical action. Textile Research Journal. https://doi.org/10.1177/0040517518821909

\section{Published in:}

Textile Research Journal

\section{Citing this paper}

Please note that where the full-text provided on Manchester Research Explorer is the Author Accepted Manuscript or Proof version this may differ from the final Published version. If citing, it is advised that you check and use the publisher's definitive version.

\section{General rights}

Copyright and moral rights for the publications made accessible in the Research Explorer are retained by the authors and/or other copyright owners and it is a condition of accessing publications that users recognise and abide by the legal requirements associated with these rights.

\section{Takedown policy}

If you believe that this document breaches copyright please refer to the University of Manchester's Takedown Procedures [http://man.ac.uk/04Y6Bo] or contact uml.scholarlycommunications@manchester.ac.uk providing relevant details, so we can investigate your claim.

\section{OPEN ACCESS}


The mechanism of wrinkling of cotton fabric in a front loading washer: the effect of mechanical action

\begin{abstract}
In order to understand the impact of mechanical action on the wrinkling of cotton fabrics in a drum washer, fabric movement was observed and a movement index system was developed to characterize the textile motion. Results showed that wash load and spinning speed were the major factors influencing the smoothness of cotton fabrics, with a p value of 0.032 and 0.00 respectively at $95 \%$ confidence level. The analysis of fabric movement illustrated that twhen the wash load increased, the free motion region decreases and the ratio of passive motion region increase, resulting in severe wrinkling of cotton fabric. A regression model was developed to characterize the relationship between fabric movement and smoothness.. These findings help the understanding of the mechanism of wrinkling during a drum washer washing.
\end{abstract}

Keywords: cotton fabrics, front-loading washer, textile dynamics, wrinkling, movement index

\title{
Introduction
}

Cotton fabrics are the most popular for clothing due to their superior properties such as softness and breathability. ${ }^{1,2}$ However, cotton fabrics are easy to wrinkle. ${ }^{3,4}$ Due to today’s fast pace of life, the use of automatic domestic washer to wash clothes is almost universal. ${ }^{5,6}$ Washing clothes in washing machine is a complicated multiphase process, which could aggravate the wrinkling problem ${ }^{7}$. Fabric wrinkling after washing is also a consideration in the purchase decision making process for consumers Therefore, it is necessary to take fabric surface property after washing into consideration in the development of new washing products..

Extensive research has been reported on the factors influencing wrinkle recovery of fabrics, for instance, Richard Steele ${ }^{8}$, Aliakbar Merati ${ }^{9}$, Chapman $^{10}$ and Krasny ${ }^{11}$. The properties of fabric are determined to a large extent by its internal structures. ${ }^{12}$ Anisotropy of wrinkle recovery exists due to the different degrees of internal yarn re-orientation and movement. ${ }^{13-15}$ A rubber model of fabric discussed the importance of inter- and intra-yarn friction on creases and wrinkles. ${ }^{16}$ Fiber type plays another important role in wrinkle formation and recovery. ${ }^{17,18}$ Hydrophilic fibers, such as cellulose fibers, swell when they absorb water molecules. The arrangement of molecular chains can be changed ${ }^{17,19}$ and the rotation along 
the fiber axis also increases due to absorption and desorption moisture, ${ }^{20}$ such that the chains can achieve higher mobility, especially in amorphous region. ${ }^{19}$ In contrast, hydrophobic fibers, such as nylon or polyester, with very low or no water absorbency will show little such effect. ${ }^{21}$ In addition to crease recovery, wrinkling and crumpling of soft sheets have been studied in recent years. For example, Douglas $^{22}$ and Huang ${ }^{23}$ studied the factors determining wrinkle sizes and shapes in soft materials under uniaxial stress. $\mathrm{Kim}^{24}$ explored the dynamic formation of wrinkles and folds of elastic membranes under biaxial compressive stress and pointed out that the morphology of the final network is influenced by the initial conditions. The criteria from wrinkle to fold also have been investigated from the perspective of material properties and the thickness of soft sheet is the main factor to influence fold formation. ${ }^{22,25}$ However, few references focus on the effect of complex mechanical action on the smoothness appearance of fabric during washing in a front loading washer.

Additionally, a number of recent studies on washing machine focus on the effect of mechanical action and washing parameters on washing performance (washing efficiency and textile properties like shrinkage and pilling) $)^{26,27}$, mass transfer during washing ${ }^{28}$, and the development of new washing type ${ }^{29}$. For example, Yun et al. ${ }^{30-33}$ established a prediction model for fabric movements according to movement indexes, and the relationship between fabric movement pattern and washing efficiency were also studied. Researchers have also studied the effect of laundry cycle and temperature on the hand, appearance, shrinkage and weight of fabrics. Water temperature has no significant effect on the properties of stabilized fabrics. ${ }^{34,35}$ The influence of washing cycles on cotton fabric properties such as drape, shear and bending are not significant. ${ }^{36,37}$ The washing process is a complex multiphase and multiscale process combining a range of physical phenomena that affect mass transfer in porous textiles. ${ }^{38-40}$ A lumped transient model with a semi-empirical character is generated to study the mechanism of detergent transportation between the inner drum and through the textiles in a top-loading washer ${ }^{28}$.Only Liu studied how fabric movement influences fabric wrinkle during top-loading washing. ${ }^{41}$ Little work has been carried out on how mechanical action influence fabric wrinkling during front loading washing.

In this study, we investigated the significant washing factors affecting wrinkle performance by ANOVA. Through the ANOVA test, washing load and spinning speed are found significant in differentiating the smoothness appearance at $95 \%$ confidence level $(\mathrm{p}<0.05)$. Textile motion was also recorded via a video capturing and processing system under different washing loads. Finally, relationships between the fabric movement and wrinkling were investigated. The outcome provides important guiding 
principles in the optimization of washing performance.

\section{Experimental and methods}

\section{Materials}

Commercial cotton fabrics were chosen as test samples. According to AATCC $124: 2010^{42}$, test samples were cut into $38 \mathrm{~cm} \times 38 \mathrm{~cm}$ squares. Moreover, in order to achieve a specific filling load in a drum washer, cotton pillowcases, mentioned in IEC $60456^{43}$ clothes washing machines for household use methods for measuring the performance, with uniform dimensions of approximately $80 \mathrm{~cm} \times 80 \mathrm{~cm}$, were placed inside the machine as the dummy wash load. The detailed information about test samples and wash load are presented in Table 1 and Table 2 respectively. Additionally, test samples were washed with soap solution followed by ordinary tap water with constant temperature at $20^{\circ} \mathrm{C}$ and laid flat to dry at room temperature in order to eliminate strain generated in production processes. All samples were conditioned at $20^{\circ} \mathrm{C}$ and $60 \% \mathrm{RH}$ for at least 24 hours.

The detergent used in this study is recommended by IEC 60456 and the proportions of components of the reference detergent are as follows: $77 \%$ base powder with enzyme and foam inhibitor, $20 \%$ sodium perborate tetrahydrate and 3\% bleach activator tetra-acetylethylenediamine(TAED).

Table 1. Geometrical properties of test samples

\begin{tabular}{ccccccc}
\hline \multirow{2}{*}{ Fiber content } & & & \multicolumn{2}{c}{ Density (yarns/5 cm) } & & \\
\cline { 4 - 5 } & Weave type & Count(Ne) & Warp & Weft & Density $\left(\mathrm{g} / \mathrm{m}^{2}\right)$ & Thickness(mm) \\
\hline \multirow{2}{*}{$100 \%$ cotton } & Plain & $40 \times 2$ & 133 & 72 & 145 & 0.79 \\
\hline
\end{tabular}

\section{Experimental design}

Orthogonal design. The washing parameters were selected relating to mechanical force and the four key influencing factors are wash load, drum rotating speed, water volume and spinning speed, as identified in the literature. ${ }^{27,44-46}$ Water temperature was not considered. Temperature could influence the viscosity of the wash medium, textile properties and mass transport in porous materials, while the change of these is not significant for textile motion. ${ }^{46}$ The levels of corresponding factors were set according to the adjustable range of the washing machine and the suggestions from manufacturer. The detailed orthogonal design is shown in Table 3, and each test with three test samples was repeated five times to 
improve accuracy.

Table 2. Orthogonal design

\begin{tabular}{ccccc}
\hline & Load & Water & Washing & Spinning \\
Test & size(Kg) & Volume(L) & speed(rpm) & speed(rpm) \\
\hline 1 & 1 & 8 & 30 & 600 \\
2 & 1 & 11 & 45 & 800 \\
3 & 1 & 14 & 60 & 1000 \\
4 & 2 & 8 & 45 & 1000 \\
5 & 2 & 11 & 60 & 600 \\
6 & 2 & 14 & 30 & 800 \\
7 & 3 & 8 & 60 & 800 \\
8 & 3 & 11 & 30 & 1000 \\
9 & 3 & 14 & 45 & 600 \\
\hline
\end{tabular}

Single factor experimental design. Wash load size and spinning speed were the major influencing factors for cotton fabric wrinkling. In the spinning process, textiles rotate with the drum, there is no significant relative motion during this period. Therefore, the movement of textiles in spinning process was not investigated. Therefore, we studied and analyzed the effect of wash load size on fabric movement and wrinkling. The detailed information of the single factor experiment is shown in Table 3.

Table 3. Washing procedures with different load size

\begin{tabular}{cccccccc}
\hline Temperature & Washing load size & Water & Washing & Rinsing & Rinsing & Spinning & Rotating \\
$\left({ }^{\circ} \mathrm{C}\right)$ & $(\mathrm{kg})$ & level & time & times & Time & time & speed \\
& & $(\mathrm{L})$ & $(\mathrm{min})$ & & $(\mathrm{min})$ & $(\mathrm{min})$ & $(\mathrm{rpm})$ \\
\hline 30 & $0.5 / 1.0 / 1.5 / 2.0 / 3.0$ & 8 & 30 & 2 & 3 & 5 & 800
\end{tabular}

\section{Wrinkle assessment}

All textile samples were line-dried under standard atmospheric conditions at $20 \pm 2^{\circ} \mathrm{C}$ and $\mathrm{RH} 60 \pm$ 5\% for 4-12 hours. And three trained assessors rated the fabrics independently based on 'AATCC 124:2010 Smoothness Appearance of Fabrics after Repeated Home Laundering, ${ }^{47}$ in a standardized 
inspection booth.

The results presented here are the mean scores of the three trained assessors.

\section{Facilities and equipment}

Washer. Experiments were carried out in a Haier WH7560P2 modified according to ISO7330:2012 with a capacity of $7 \mathrm{Kg}$. The front door of the washer was made by transparent glass for easier observation of the textile movement. The diameter of the inner drum is $490 \mathrm{~mm}$ and the depth is $275 \mathrm{~mm}$.

Recording the fabric movements. Fabric movement was recorded by a high speed camera GoProHERO 5 at a speed of 120 frames per sec. The tracer textile is yellow, as shown in Fig.1 (a). In order to analyze the recorded fabric movement, the image was converted to binary image by threshholding, as shown in Fig.1 (b). The threshold range is between 30 to 50 in hue. The connected component analysis and image moment were applied to compute the centroid of the binary image. ${ }^{48,49}$ Finally, the central moment of binary image was converted to the centroid of movement of fabrics according to a certain position of the drum in a Cartesian coordinate system. No detergent was used for convenient observation of textile movement.

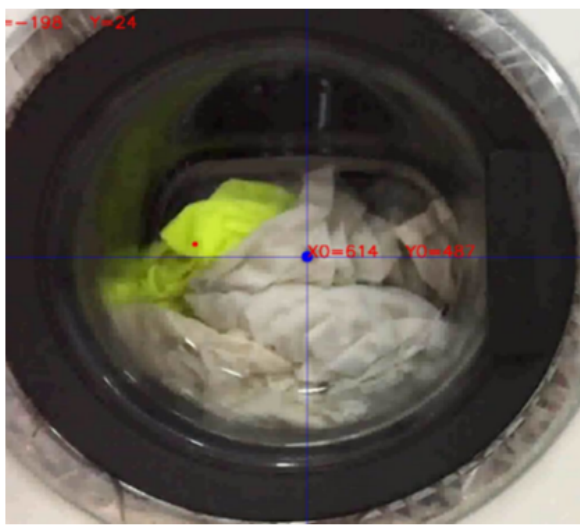

(a)

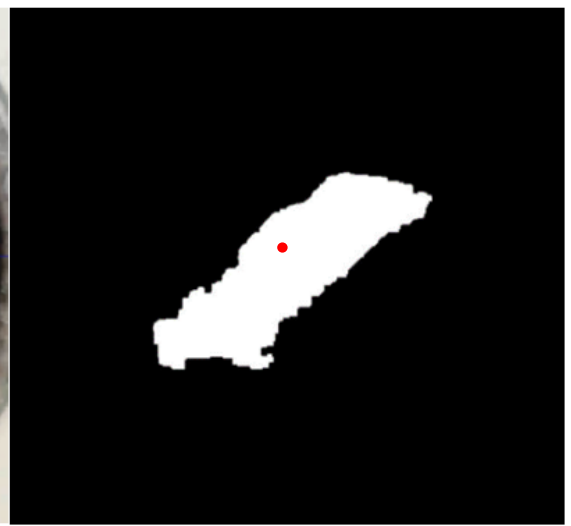

(b)

Figure 1. Recording the fabric movement ((a) tracer textile in washing machine; (b) binary image of tracer textile and centroid of connected region (red point))

\section{Results and discussion}

\section{Effects of washing machine parameters on the cotton fabric smoothness}

According to Table 4, the smoothness grade decreased from 2.0 to 1.4 for higher wash load, indicating that the wash load affects the wrinkling performance of cotton fabric significantly. This difference is probably due to the decreasing free motion space of fabric in the drum, and thus limiting the 
space for fabrics to spread and flatten. The complex mechanical action ${ }^{46}$ imposed on fabrics including shear stress and tension/compression stress varies with different wash load. This also aggravates the wrinkling. Previous study showed that faster washing and spinning speeds increase the amount of wrinkling because of the relative motion of fabrics and fluids in a top loading washer. ${ }^{41}$ However, the drum speed and water volume have no significant influence on wrinkling of cotton fabrics in a front loading washer. Fabric smoothness decreases with the increase of spinning speed.

Wrinkling is plastic deformation of fabric that fails to return to its original position after removing the force or load. Fiber properties, fabric structure and the mechanical forces have significant influence on the degree of wrinkle. ${ }^{17,50}$ Cotton fiber contains approximately $47.1 \%-50.7 \%$ amorphous region . ${ }^{7}$ During front-loading washing, cotton fabrics are wetted and water molecules bond with hydrophilic groups in the non-crystalline region. The rearrangement of the molecule chains in amorphous regions is easy, resulting in both easy deformation and deformation recovery.${ }^{51}$ As a result, wrinkles formed during washing process are active and temporary. In contrast, during spinning, the internal pores in the fibers collapse with water removal, leading to the formation of irreversible or partially reversible hydrogen bonds. ${ }^{52,53}$ The plastic stress for most glassy polymers ${ }^{25}$ can be calculated on the basis of $\sigma_{0} \approx E \times 3.3 \times 10^{-2}$. The average spin speed of modern front loading washer is usually higher than 800rpm for cotton washing procedure, the compression stress due to centrifugal force is higher than the plastic stress $(11.57 \sim 30.7 \times$ $10^{6} \mathrm{MPa}$ (compression stress) 》174.9 264 MPa(plastic stress of cotton fiber)), thus permanent wrinkles form. In conclusion, wrinkles formed during washing process are temporary while fixed creases mainly form during spinning. Cotton fabrics are soft material and wrinkle easily under tension and shear. ${ }^{12,54}$ In washing process, the movement of textiles is complex, increasing the chance of wrinkling. These temporary creases formed during washing process will transfer into permanent and fixed wrinkles during spinning and drying process.

Table 4. Orthogonal design results

\begin{tabular}{ccccccc}
\hline & Load & Water & Washing & Spinning & Smoothness & Standard deviation \\
Test & size(Kg) & Volume(L) & speed(rpm) & speed(rpm) & appearance(grade) & appearance \\
\hline 1 & 1 & 8 & 30 & 600 & 1.9 & 0.1 \\
2 & 1 & 11 & 45 & 800 & 2.0 & 0.1 \\
\hline
\end{tabular}




\begin{tabular}{lllllll}
\hline 3 & 1 & 14 & 60 & 1000 & 1.9 & 0.2 \\
4 & 2 & 8 & 45 & 1000 & 1.4 & 0.1 \\
5 & 2 & 11 & 60 & 600 & 1.5 & 0.2 \\
6 & 2 & 14 & 30 & 800 & 1.7 & 0 \\
7 & 3 & 8 & 60 & 800 & 1.5 & 0.1 \\
8 & 3 & 11 & 30 & 1000 & 1.4 & 0.1 \\
9 & 3 & 14 & 45 & 600 & 1.4 & 0 \\
\hline
\end{tabular}

The results of ANOVA test was used to screen the significant factors affecting the fabric smoothness. Washing load size and spin speed are found to be significant in differentiating the smoothness appearance at $95 \%$ confidence lever with p value of 0.032 and 0.00 respectively.

\section{Analysis of fabric movements during washing}

During washing, there is little fabric movement in the drum axial direction ${ }^{27}$. The fabric axial movement was therefore ignored in this study.

\section{Velocity distribution with different wash load size}

The estimated Eulerian velocity ${ }^{27}$ is the time weighted average of all of the Lagrangian data. And Lagrangian velocity ${ }^{55}$ is calculated based on the trajectory of tracer textile. The detailed information and illustration of velocity calculation can be found in the paper cited above. From Fig 2, we can see that there are two regions in the velocity contour plots of textile motion. A passive region situated in the left-side drum wall where textiles are lifted by the drum wall and an active region where textiles fall freely with a higher velocity than that of passive region. The size of passive region increases with the wash load. This is due to the decrease of free motion area for textiles (the volume of inner drum without wet textiles). In the active region, textile has more chance to spread, resulting in wrinkle recovery. In contrast, textiles move as a packed fabric plug in the passive region following the drum rotation at a relative slower speed. The compression and shear force from adjacent textiles increase with wash load, leading to wrinkle formation in the passive region. Figure 3 shows the effect of wash load on the textiles exchange frequency from the wall to the central region of the inner drum (a centric circle with centers located at the center of the inner drum with radius $120 \mathrm{~mm}$ ). The exchange frequency is a function of wash load and decreases with the load. This means that it is easy for the textile to be trapped in a specific 
region and difficult to move out. This may exaggerate wrinkle formation.

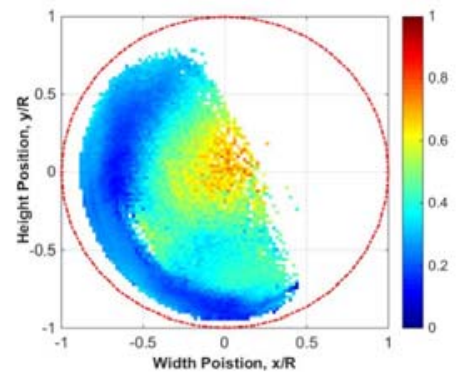

$0.5 \mathrm{~kg}$

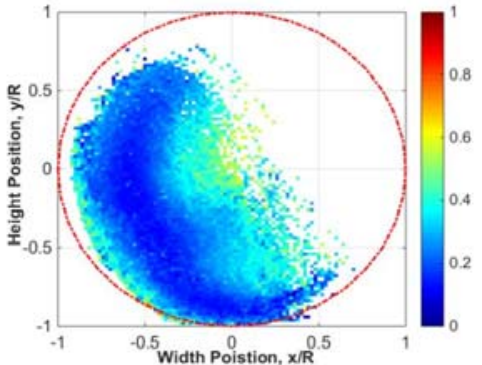

$1.0 \mathrm{~kg}$

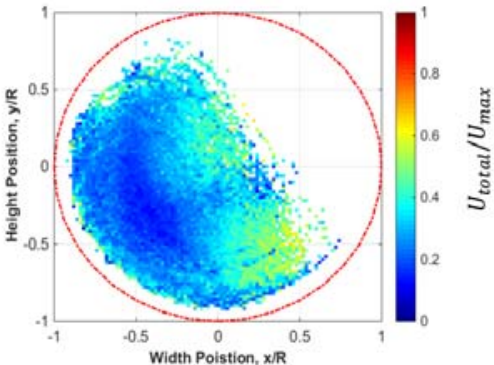

$1.5 \mathrm{~kg}$

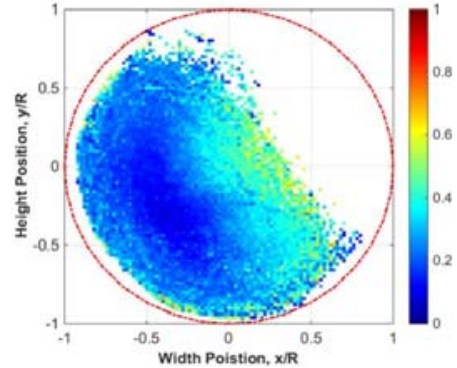

$2.0 \mathrm{~kg}$

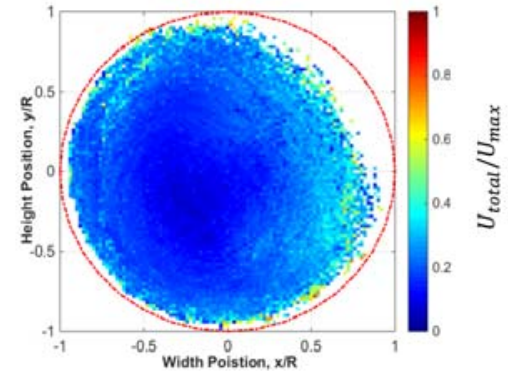

$3.0 \mathrm{~kg}$

Figure 2. Eulerain velocity distribution with different wash load size

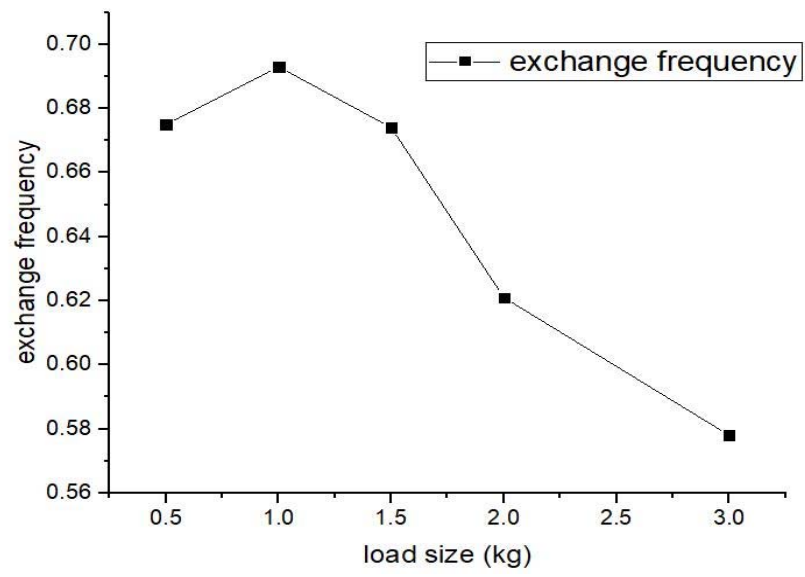

Figure 3. Exchange frequency form wall to the center region of the inner drum with different wash load

\section{Correlation between fabric movement and smoothness}

Fabric movement index. In order to analyzing the correlation between fabric movement and smoothness, an index system was established to characterize the fabric movements. Eight movement indexes are shown in Table 5. Some of the indexes were defined by Yun et al. ${ }^{31}$

Table 5. Fabric movement indexes

\begin{tabular}{c|c|c|c}
\hline Index & Concept map & Index & Concept map \\
\hline
\end{tabular}




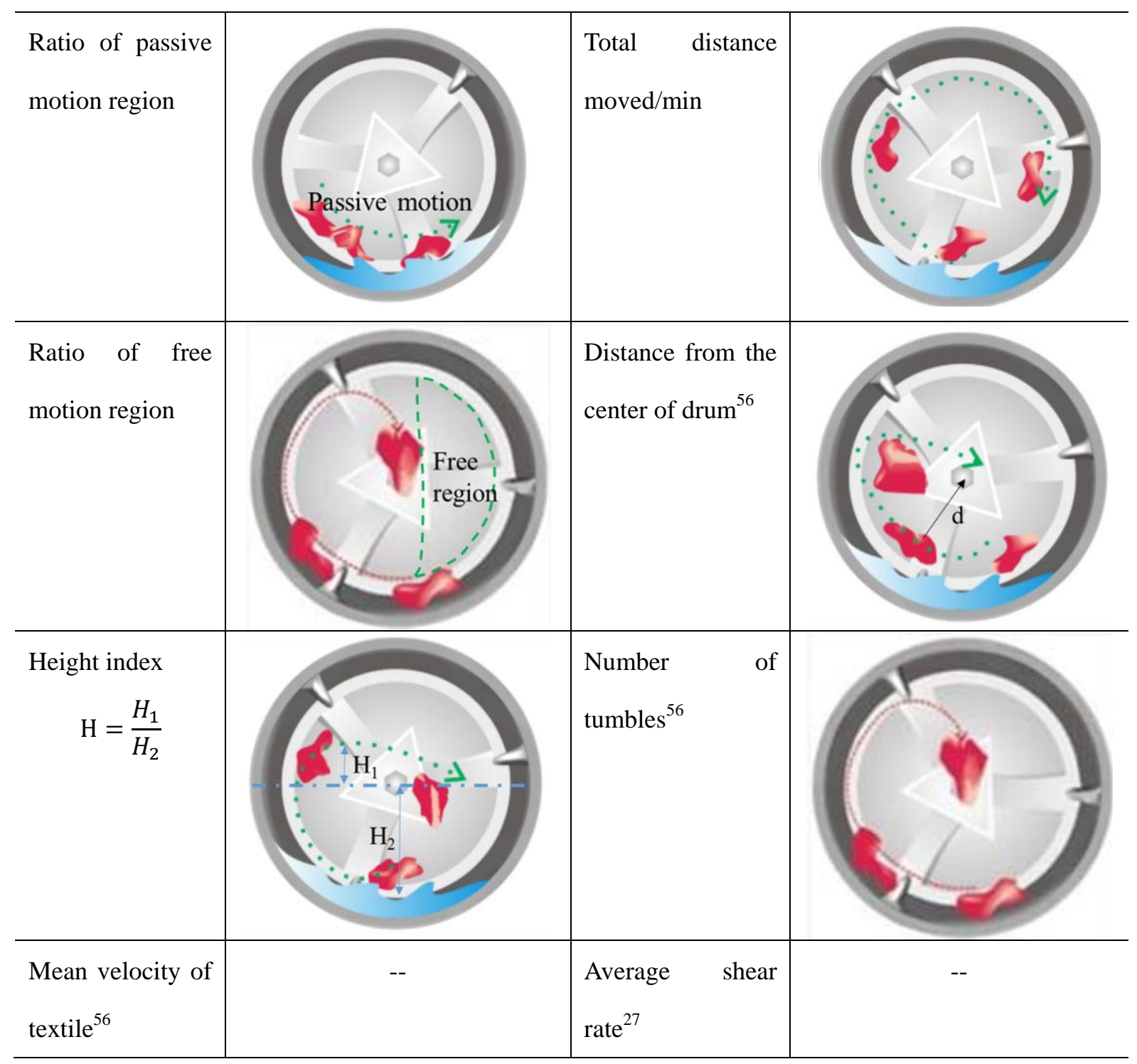

Note: Passive motion region is the area where textile moves up with the drum and with a slow speed; free motion region is the area where textile can spread and flatten. $\mathrm{H}_{1}$ is the maximum height the textile could reach when rotating; $\mathrm{H}_{2}$ is the vertical distance from the centroid of the tracer textile to the center when at the bottom of the drum; Shear rate is the gradient of Eulerian velocities across adjacent specific region.

Bivariate (Pearson) correlation tests were conducted to screen fabric movement indexes which had high correlation with smoothness of fabrics. From the comparison, the ratio of passive motion area has strong negative correlation with smoothness, while the distance from the center of the drum and ratio of free motion region have positive correlation with cotton fabric wrinkles. These three index values and the smoothness of different textile mass are shown in Table 6. In the passive region, textiles pack together. Compression and shear force from adjacent textiles aggravate wrinkle formation. Large free motion region allows fabric to spread, thus increasing wrinkle recovery. The nearer of the textile is to the center 
of the drum, the easier it is for the textile to bunch up, resulting in more serious deformation of textile.

Table 6. Fabric movement index values and grade of smoothness for different wash load

\begin{tabular}{ccccccc}
\hline Movement Index & $0.5 \mathrm{~kg}$ & $1.0 \mathrm{~kg}$ & $1.5 \mathrm{~kg}$ & $2 \mathrm{~kg}$ & $3 \mathrm{~kg}$ & \multicolumn{2}{c}{ Correlations with } \\
& & & & & & Smoothness \\
\hline Ratio of passive motion area (\%) & 0.299 & 0.6229 & 0.5078 & 0.7947 & 0.9816 & -0.966 \\
Ratio of free motion region (\%) & 0.6184 & 0.5317 & 0.4884 & 0.4598 & 0.171 & 0.856 \\
Distance from the center of drum (m) & 0.104 & 0.103 & 0.093 & 0.090 & 0.0774 & 0.904 \\
Smoothness & 2.5 & 1.9 & 1.8 & 1.3 & 1.1 & 1 \\
\hline
\end{tabular}

Regression equation for smoothness in fabric. The stepwise regression analysis was conducted for the smoothness by setting the fabric movement index as an independent variable, in order to determine the correlation between fabric movement and wrinkling. The statistical analysis results for the regression equation are shown in Table 7. The regression equation for the smoothness is as follows:

$$
\text { Grade of smoothness }=3.09-2.026 x
$$

Where, $x$ is the ratio of passive motion region. The adjusted $\mathrm{R}$ square is 0.911 .

For the smoothness, only the ratio of passive motion region satisfies the criteria of stepping method with entry threshold $\mathrm{p}<0.05$ and removal threshold $\mathrm{p}>0.1$. As we discussed above, the passive motion region increases with the increase of textiles mass, where textiles are trapped or restricted by adjacent textiles. Textiles wrinkle easily in shear, compression or tension. Compression force or shear force from other textiles aggravate the wrinkle of textiles. In this situation, fabrics may experience more complex mechanical force, resulting in severe wrinkling. There is no relative motion of textiles during spinning due to high rotational speed, resulting in less bend or torsion of textiles. Therefore, temporary creases occurring in washing process because of complex mechanical action will transfer into permanent and fixed wrinkles during spinning. In conclusion, final smoothness is influenced by both washing process and spinning process.

Table 7. Statistical analysis results for regression equations

\begin{tabular}{lllllll}
\hline & Unstandardized & & Standardized & & \\
Coefficients & Coefficients & & \\
Model & B & Std. Error & Beta & t & Sig. \\
\hline
\end{tabular}




\begin{tabular}{lccccc}
\hline (Constant) & 3.019 & 0.214 & & 14.114 & 0.001 \\
Ratio of passive motion & & & & & \\
& -2.026 & 0.313 & -0.966 & -6.466 & 0.008 \\
region (\%) & & & & & \\
\hline
\end{tabular}

\section{Conclusion}

Wash load and spinning speed are found to be the major parameters that affect cotton fabric wrinkling. The analysis of fabric movement during drum washer washing illustrates that the higher the washing load is, the larger the passive motion region is. Larger passive motion region leads to more complex mechanical action on the fabrics due to shear stress or tension/compression stress from adjacent textiles and the drum, thus causing severe wrinkling. A fabric movement index system was established to characterize the motion of the textile. Wrinkle performance and mechanical action were represented by the movement indexes. The ratio of passive motion and the distance from the center of the drum have strong influence on smoothness. A regression model to predict the smoothness has been developed, which shows that the smaller is the ratio of passive motion region, the higher is the smoothness. These findings deepens the understanding of textile dynamics in a front loading washer and provides valuable information for washer manufacturers and consumers to improve machine design and clothes care.

\section{Funding}

This research was supported by the National Natural Science Foundation of China (71373041 and 61702460), Donghua University (CUSF-DH-D-2017078 \& ISN2017-3) and Zhejiang Sci-Tech University (17072067) respectively, the Shanghai Science and Technology Committee (17DZ2202900), the National Key R\&D Program of China (2018YFF0215730), Shanghai Summit Discipline in Design (DD18005), and general research projects of Zhejiang Provincial Department of Education (Y201738456).

\section{Reference}

1. Ibrahim HM and Hassan MS. Characterization and antimicrobial properties of cotton fabric loaded with green synthesized silver nanoparticles. Carbohydrate polymers. 2016; 151: 841-50.

2. Poon C-k and Kan C-w. Relationship between curing temperature and low stress mechanical properties of titanium dioxide catalyzed flame retardant finished cotton fabric. Fibers and polymers. 2016; 17: 380.

3. Dehabadi VA, Buschmann H-J and Gutmann JS. Durable press finishing of cotton fabrics: an overview. Textile Research Journal. 2013; 83: 1974-95. 
4. Schindler W and Hauser P. Easy-care and durable press finishes of cellulosics. Chemical finishing of textiles. 2004: 51-72.

5. Wang L, Ding X, Huang R and Wu X. Choices and using of washing machines in Chinese households. International Journal of Consumer Studies. 2014; 38: 104-9.

6. Hustvedt G, Ahn M and Emmel J. The adoption of sustainable laundry technologies by US consumers. International Journal of Consumer Studies. 2013; 37: 291-8.

7. Wei $Y$, Gong RH, Ning $L$ and Ding $X$. Research on physical properties change and damage behavior of cotton fabrics dried in drum-dryer. The Journal of The Textile Institute. 2017: 1-12.

8. Steele R. The effect of yarn twist on fabric crease recovery. Textile Research Journal. 1956; 26: 739-44.

9. Merati A and Patir H. Anisotropy in wrinkle properties of woven fabric. The Journal of The Textile Institute. 2011; 102: 639-46.

10. Chapman B. The Bending and Creasing of Multicomponent Viscoelastic Fiber Assemblies: Part III: The Mechanics of a Two-Dimensional Assembly of Generalized Linear Viscoelastic Fibers of Different Types. Textile Research Journal. 1974; 44: 306-9.

11. Krasny J, Mallory G, Phillips J and Sookne A. Part II: Effect of construction on crease recovery of fortisan fabrics. Textile Research Journal. 1955; 25: 499-506.

12. Pan N, He J-H and Yu J. Fibrous materials as soft matter. Textile research journal. 2007; 77: 205-13.

13. Wang L, Liu J, Pan R and Gao W. Exploring the relationship between bending property and crease recovery of woven fabrics. The Journal of the Textile Institute. 2015; 106: 1173-9.

14. Fridrichová L, Zelová K and Knížek R. Influence of Structure of Material on Properties of Bending Rigidity and Creasing in Different Directions. Advanced Science Letters. 2013; 19: 384-7.

15. Pan N. Exploring the significance of structural hierarchy in material systems-A review. Applied Physics Reviews. 2014; 1: 021302.

16. Chapman B and Hearle J. 27-THE BENDING AND CREASING OF MULTICOMPONENT VISCOELASTIC FIBRE ASSEMBLIES. PART I: GENERAL CONSIDERATION OF THE PROBLEM. Journal of the Textile Institute. 1972; 63: 385-403.

17. Široká B, Manian AP, Noisternig MF, et al. Wash - dry cycle induced changes in low - ordered parts of regenerated cellulosic fibers. Journal of Applied Polymer Science. 2012; 126.

18. Wang L, Liu J, Pan R, Liu J and Gao W. Automatic Measurement of Fabric Crease Recovery by Image Sequence Analysis. Journal of Testing and Evaluation. 2014; 43: 499-506.

19. Hartley I, Kamke F and Peemoeller H. Cluster theory for water sorption in wood. Wood Science and Technology. 1992; 26: 83-99.

20. Mannan KM and Robbany Z. Rotation of a natural cellulosic fibre about its fibre axis due to absorption of moisture. Polymer. 1996; 37: 4639-41.

21. Liang S, Pan N, Wu X and Ding X. Effects of pressure-free steam ironing on cotton fabric surfaces and wrinkle recovery. Textile Research Journal. 2017: 0040517517725124.

22. Holmes DP and Crosby AJ. Draping films: A wrinkle to fold transition. Physical review letters. 2010; 105: 038303.

23. Huang J, Davidovitch B, Santangelo CD, Russell TP and Menon N. Smooth cascade of wrinkles at the edge of a floating elastic film. Physical review letters. 2010; 105: 038302.

24. Kim P, Abkarian $M$ and Stone HA. Hierarchical folding of elastic membranes under biaxial compressive stress. Nature materials. 2011; 10: 952.

25. Benusiglio A, Mansard V, Biance A-L and Bocquet L. The anatomy of a crease, from folding to ironing. Soft Matter. 2012; 8: 3342-7. 
26. Lee A, Seo MH, Yang S, Koh J and Kim H. The effects of mechanical actions on washing efficiency. Fibers and Polymers. 2008; 9: 101-6.

27. Mac Namara C, Gabriele A, Amador C and Bakalis S. Dynamics of textile motion in a front-loading domestic washing machine. Chemical Engineering Science. 2012; 75: 14-27.

28. Campos LG and Hermes CJ. Experimental evaluation and transient simulation of detergent transport in household vertical axis washing machines. Chemical Engineering Research and Design. 2016; 109: 720-9.

29. Gotoh K, Harayama K and Handa K. Combination effect of ultrasound and shake as a mechanical action for textile cleaning. Ultrasonics Sonochemistry. 2015; 22: 412-21.

30. Park S, Yun C, Kim J and Park $\mathrm{CH}$. The effects of the fabric properties on fabric movement and the prediction of the fabric movements in a front-loading washer. Textile Research Journal. 2013; 83: 1201-12.

31. Yun C, Park S and Park CH. The effect of fabric movement on washing performance in a front-loading washer. Textile Research Journal. 2013; 83: 1786-95.

32. Yun $\mathrm{C}$ and Park $\mathrm{CH}$. The effect of fabric movement on washing performance in a front-loading washer II: under various physical washing conditions. Textile Research Journal. 2015; 85: 251-61.

33. Yun $\mathrm{C}$ and Park $\mathrm{CH}$. The effect of fabric movement on washing performance in a front-loading washer III: Focus on the optimized movement algorithm. Textile Research Journal. 2016; 86: 563-72.

34. Van Amber RR, Niven BE and Wilson CA. Effects of laundering and water temperature on the properties of silk and silk-blend knitted fabrics. Textile Research Journal. 2010; 80: 1557-68.

35. Morris MA. . Laundering Cotton Fabric: Part II: Effect of Detergent Type and Water Temperature on Appearance, Hand, Strength, and Cost. Textile Research Journal. 1970; 40: 644-9.

36. Militky J and Bajzik V. Influence of washing/ironing cycles on selected properties of cotton type weaves. International Journal of Clothing Science and Technology. 1997; 9: 193-9.

37. Orzada BT, Moore MA, Collier BJ and Yan Chen J. Effect of laundering on fabric drape, bending and shear. International Journal of Clothing Science and Technology. 2009; 21: 44-55.

38. Tuzson J and Short BA. Mass transfer and the washing process. Textile Research Journal. 1960; 30: 983-9.

39. Van Den Brekel LDM. Hydrodynamics and mass transfer in domestic drum-type fabric washing machines. ICG-Printing Dordrecht, 1987.

40. Van der Donck J, So A and Frens G. The influence of stretching on salt release from porous yarns. Tenside, surfactants, detergents. 1998; 35: 119-22.

41. Liu H, Wang Y, Gong RH, Zeng J and Ding X. The relationships between washing parameters, fabric movement, and wrinkling in a top-loading washer. Textile Research Journal. 2017: 0040517517700197.

42. AATCC. Smoothness appearance of fabrics after repeated home laundering. AATCC Test Method 124-2010. US: The American Association of Textile Chemists and Colorists, 2010, p. 195-8.

43. IEC. Clothes washing machines for household use-Methods for measuring the performance. Switzerland: International Electrotechnical Commission, 2010, p. 1-146.

44. Balt A, van den Brekel L, Vandecasteele C and Kolar Z. Radiotracer study of wash load movement in a drum-type fabric washing machine using a gamma camera. International Journal of Radiation Applications and Instrumentation Part A Applied Radiation and Isotopes. 1987; 38: 7-12.

45. Yun $\mathrm{C}$ and Park $\mathrm{CH}$. The effect of fabric movement on washing performance in a front-loading washer III: Focus on the optimized movement algorithm. Textile Research Journal. 2015: 0040517515590417.

46. Mac Namara C, Amador C and Bakalis S. The physics of washing machines. University of Birmingham, 2014.

47. AATCC. Smoothness apperance of fabrics after repeated home laundering. 2010.

48. Mukundan R and Ramakrishnan K. Moment functions in image analysis-theory and applications. World 
Scientific, 1998.

49. Kaehler A and Bradski G. Learning OpenCV 3: Computer Vision in C++ with the OpenCV Library. " O'Reilly Media, Inc.", 2016.

50. Hearle J. A fringed fibril theory of structure in crystalline polymers. Journal of Polymer Science Part A: Polymer Chemistry. 1958; 28: 432-5.

51. Siroka B, Manian AP, Noisternig MF, et al. Wash-dry cycle induced changes in low-ordered parts of regenerated cellulosic fibers. Journal of Applied Polymer Science. 2012; 126: E396-E407.

52. Park S. Drying Behavior of Cellulose Fibers Characterized by Thermal Analysis. 2007.

53. Maloney TC, Johansson $\mathrm{T}$ and Paulapuro $\mathrm{H}$. Removal of water from the cell wall during drying. Paper Technology. 1998; 39: 39-47.

54. Cerda E and Mahadevan L. Geometry and physics of wrinkling. Physical review letters. 2003; $90: 074302$.

55. Bakalis S, Fryer $P$ and Parker D. Measuring velocity distributions of viscous fluids using positron emission particle tracking (PEPT). AIChE journal. 2004; 50: 1606-13.

56. Yun C, Park S and Park $\mathrm{CH}$. The effect of fabric movement on washing performance in a front-loading washer. Textile Research Journal. 2013: 0040517512452927. 